\title{
A Review of the Empirical Literature on Meaningful Work: Progress and Research Agenda
}

\begin{abstract}
Meaningful work is a topic of importance in core domains of HRD such as employee engagement and understandings of human performance and potentiality. However, there is little consensus over what comprises meaningful work, or concerning the antecedent and outcome factors associated with meaningfulness. Prior theorizing has tended to conflate conceptual and empirical arguments, and hence we lack clear insight into factors related to the experience of meaningfulness. We address this by presenting the results of an analysis of the empirical literature relating to meaningful work. 71 studies met the inclusion criteria. Our aim is to address the question: what is the empirical evidence base concerning meaningful work, and how can this inform theory and practice in HRD? The synthesis reveals dominant trends alongside significant gaps in understanding. We highlight the practical implications of our analysis for the HRD field, and propose avenues for future research on meaningfulness within HRD.
\end{abstract}

\section{Introduction}

Meaningful work has become a topic of interest among scholars and practitioners in recent years due, in part, to a dissatisfaction with short-termist organizational imperatives, growing concerns over job quality, and a burgeoning focus on work as an arena for individuals to find meaning and purpose (Chalofsky, 2010; Lepisto \& Pratt, 2017; Taylor, 2017). While the current vogue for meaningful work is welcome, the subject has been the focus of scholarly attention in the humanities for many centuries, laying a rich theoretical foundation for understanding work's 
potential as a meaningful human endeavor (Berkelaar \& Buzzanell, 2015; Tablan, 2015; Yeoman, 2014).

Within the human resource development (HRD) field, meaningfulness has come to the fore through its association with high levels of engagement (Alagaraja \& Shuck, 2015; Fairlie, 2011; Kahn, 1990; Shuck, 2011), as well as interest in human purpose and potentiality (Chalofsky \& Cavallero, 2013; Chalofsky \& Krishna, 2009; Fairlie, 2011). However, HRD scholars have also drawn attention to the dearth of empirical research on the topic (Chalofsky, 2003; Cullen, 2013; Kuchinke et al., 2009). For example, Thory (2016: 58) notes: 'there remains a significant gap in the human resource development literature in understanding how training and development contributes to meaningful work'. This gap would appear significant, given the leading role HRD can play in developing the working conditions that might promote a sense of meaningfulness (Chalofsky, 2010).

Earlier reviews of the literature in the HRD, organizational behavior and ethics fields have expanded our knowledge of the core dimensions of meaningful work (e.g. Chalofsky, 2003; Lepisto \& Pratt, 2017; Michaelson, Pratt, Grant \& Dunn, 2014; Rosso, Dekas \& Wrzesniewski, 2010). However, important questions remain unanswered. In particular, no prior review specifically focusing on the empirical evidence has been conducted, and so we lack understanding of how meaningful work is in fact experienced by employees, and of the organizational and individual level factors that may serve to promote a sense of meaningfulness.

From the perspective of HRD, this dearth of knowledge is troublesome because meaningfulness plays a central role in a number of core HRD debates. First, meaningfulness is a fundamental 
component of workplace spirituality (Dirkx, 2001; 2013), which stresses the importance of acknowledging the inner self and soul at work (Pardasani, Sharma \& Bindlish, 2014; Petchsawang \& Duchon, 2009). According to this perspective, the employer has a responsibility to nurture a working environment that instils a sense of purpose, community and belonging (Adawiyah \& Pramuka, 2017; Daniel, 2010; Marques, 2006). Another strand of the HRD literature is concerned with how employees' sense of meaningfulness can be enhanced through learning and development interventions; for example, Thory (2016) showed how emotional intelligence training can serve to promote an increased sense of meaningfulness through enabling insights into one's own and others' emotions. Third, meaningfulness interacts with work-life balance in the notion of the work-life system (Munn, 2013) as well as being relevant for understanding individuals' career behavior (Cullen, 2013). Moreover, meaningfulness is salient in debates around job design, whereby job design elements that foster a sense of meaningfulness may lead to higher levels of job satisfaction, motivation and performance and reduced levels of absenteeism and turnover (Garg \& Rastogi, 2006; Hackman \& Oldham, 1976). In sum, as Chalofsky (2003) argued, meaningfulness implies an inclusive state of being and is a significant contributor to individuals' sense that they have achieved their purpose in life, which is important not just for employees' mental health but also for healthy, high-performing organizations. Given the centrality of meaningfulness to important debates such as these within the HRD field, there is a pressing need to understand more about what the evidence base for meaningful work.

The aim of this paper is to present the findings of a systematic review of the empirical literature on meaningful work to establish the contours of knowledge concerning the experience, antecedents and outcomes of meaningfulness. Given the growth in empirical research on meaningful work that has taken place in recent years (Lepisto \& Pratt, 2017), particularly since 
Chalofsky (2003) concluded that relatively few studies had been undertaken, such a review is both timely and warranted for the HRD community.

The over-arching aim of our study is to address the question: what is the empirical evidence base concerning meaningful work, and how can this inform theory and practice in HRD? This question is broken down into five sub-questions as follows:

RQ1 How has meaningful work been (a) defined and (b) measured and assessed in the empirical literature?

RQ2 How has meaningful work been theorized in empirical studies?

RQ3 What outcomes at the individual, organizational and societal level have been found to be associated with meaningful work?

RQ4 What evidence is there concerning organizational practices/antecedents that are associated with the experience of meaningful work?

RQ5 What evidence is there concerning individual differences associated with the experience of meaningful work, as antecedents or as moderating/mediating factors?

First, we outline the methods used to search for and extract data from relevant articles, and the decisions made about inclusion criteria. We then address each of our research questions, before analyzing and synthesizing the evidence base and setting out an agenda for future research and practice in the HRD domain. 


\section{Methods}

To conduct this review, we undertook a systematic review of the empirical literature. We followed the recommended procedure described by Briner and Denyer (2010) through five stages of: planning and scoping; undertaking a structured search; evaluating search results against agreed criteria; extracting evidence from the included items, and developing analysis/synthesis findings for dissemination.

In the planning and scoping stage, we developed and refined our five research questions and piloted the search of databases using the key terms 'meaningful work' and 'meaning* work' as well as the related terms 'worthwhile work', 'decent work', 'ethical meaning of work', and 'good work' along with combinations of terms (e.g. 'meaning* work AND contribution'). These additional terms were included at this stage to ensure that we cast a wide net and did not inadvertently omit any important literature. These additional search terms that included phrases we found in our initial literature review to signify constructs similar to meaningfulness. Our initial scoping of these terms across five different databases (Business Source Complete, International Bibliography for the Social Sciences, PsychINFO, PsychARTICLES and Scopus) using open field searches yielded 42,498 results. Analysis of these results suggested the need for a more focused search strategy by using a search string based on fewer terms since the additional terms we had included did not yield relevant material, but also for adding a greater number of databases to be more inclusive of different sources.

For the structured search we used the original five databases listed above, and also Proquest, PubMed and Zetoc. These databases were chosen because they cover a very wide range of peer- 
reviewed journals across the social sciences. We used the search string '(meaningful OR worthwhile OR good OR decent) AND work' which produced 1,431 results. To this, further items were added manually through citation tracking, footnote searching and on the recommendation of other scholars. To determine our date range, we agreed that 1950 was an important milestone given the growing interest in work motivation and job characteristics after the Second World War (Yeoman, 2014). We confined our search to studies published in English between 1950-2017 which contained empirical data obtained from individuals in employment. Given Chalofsky's (2007) contention that the HRD field is one with interdisciplinary foundations, we deliberately sought to include empirical studies from adjacent disciplines such as human resource management, management, organizational behaviour, sociology and ethics.

In light of the interchangeable way in which the terms 'meaning of work' and 'meaningful work' have been used (Rosso et al., 2010), studies that used the term 'meaning' rather than 'meaningfulness' were scrutinized individually to ascertain whether their primary focus was on the 'meaning of' work, in which case they were excluded, or on 'meaningful work', in which case they were included. It is important to note that the 'meaning of' and 'meaningful' work are not synonymous (Chalofsky, 2010; Lips-Wiersma \& Morris, 2009). Baumeister (1991, p. 15), for example, stated that meaning is 'a mental representation of possible relationships among things, events, and relationships. Thus, meaning connects things.' Work may therefore have a variety of both instrumental and expressive meanings (Kuchinke, Cornachione, Oh \& Kang, 2010), such as representing a source of disutility, freedom, commodity, self-fulfilment or identity (Budd, 2011), whereas meaningfulness connotes an inclusive state of being (Chalofsky, 2010). Moreover, following Chalofsky (2010), our focus here is on 'meaningful work' or 'meaning in work', rather 
than 'meaning at work' which is a narrower term implying the relationship between the individual and the employer.

The results were filtered by including only peer-reviewed items to ensure quality and reliability and by using the 'de-duplication' function in the Refworks (Version 4) bibliographic management software, which brought the number of search results for evaluation to 422 . In this process, we excluded books, book chapters, conference papers and other grey literature to keep the search manageable. In the third stage, we evaluated the search results by initially completing a number of trial sifts including all team members. This entailed all team members evaluating whether the same items should be included or excluded. We continued this process until an acceptable level of inter-rater consensus as determined by a kappa score of 0.78 , within the range described by Viera and Garret (2005, p. 361) as 'substantial agreement', was reached. During this stage, we excluded a total of 352 papers that did not meet the pre-sift inclusion criteria. This left a total of 71 items for data extraction which were then downloaded in full from respective databases. The fourth stage of data extraction was undertaken using a pro-forma for each of the research questions. The final stage of the review involves analysis and synthesis prior to dissemination. To facilitate this, each team member took the lead in analysing extracted data according to individual research questions, and we developed detailed summary tables that provided a comprehensive overview of the study findings in relation to each research question and their inter-linkages. These tables were used in team discussions about the data and informed the development of a shared narrative about the results, developing sub-themes to capture the range of findings under each heading and to reflect the complexity of the emergent evidence base. 


\section{Overview of Included Studies}

Fifty-two percent of the included studies used cross-sectional self-report surveys, while $10 \%$ were longitudinal, time-lagged or diary studies; $7 \%$ used a survey issued to dyads (e.g. managers and employees); 7\% used a survey and outcome or performance data from another source e.g. manager performance ratings, one of which also used qualitative methods; $4 \%$ used mixed qualitative and quantitative approaches; and $20 \%$ adopted purely qualitative methods including interviews, observations, focus groups, documentary analysis and action research. Most studies took place in North America, and a minority of studies had also been conducted in Europe, Australasia, the Far East, Israel, India, South Africa and the Philippines.

\section{Results: Definitions and Measures of Meaningful Work}

There was no consensus over the definition of meaningful work across all the papers we reviewed. Allied to this, we found that in the quantitative studies, a total of 28 different scales had been used to measure meaningful work. A surprisingly significant minority of studies failed to provide any definition of meaningful work at all, or simply defined it self-referentially as work that is subjectively meaningful to the individual (e.g. Bunderson \& Thompson, 2009; Leiter \& Harvie, 1997; Mather, 2008). Another small group of scholars defined meaningful work as a onedimensional construct (e.g. Carton, 2017; Munn, 2013; Renard \& Snelgar, 2016). For instance, Bassi, Bacher, Negri and Delle Fave (2013) argued that meaningfulness is a eudaimonic concept comprising perceived job significance. Several of these studies used a single item measure to evaluate meaningfulness (e.g. Bassi et al., 2013; Munn, 2013). Our analysis of the array of 
measures and conceptualizations of meaningfulness yielded six dominant perspectives (see Table $1)$.

Table 1 about here

Meaningfulness derived from the job characteristics model: The job characteristics model was an early attempt to map the terrain of meaningfulness within the empirical literature in which Hackman and Oldham (1975) positioned meaningfulness as one of a set of psychological states that mediate relationships between three job design features: skill variety, task significance and task identity, and a number of outcomes. Several studies have drawn on this approach (Johns, Xie \& Fang, 1992; Rafferty \& Restubog, 2011; Idasazak, Bottom \& Drasgow, 1987). As this research perspective has gained traction over time, some researchers have begun to rely on the job characteristics as a measure for meaningful work, rather than measuring the construct itself (e.g. Piccolo \& Colquitt, 2006).

A number of separate strands within the subsequent empirical literature derive from the conceptualization of meaningfulness inherent in the job characteristics model. For example, an important line of research on personal role engagement that began with the qualitative work of Kahn (1990) draws upon the job characteristics model to argue that psychological meaningfulness is an antecedent to engagement. Kahn (1990, p. 704) defined meaningfulness as: 'a feeling that one is receiving a return on investments in one's self in a currency of physical, cognitive or emotional energy that arises from undertaking work that is worthwhile, useful and valuable'. Several quantitative studies have subsequently tested out his model using surveys and diary studies (e.g. Chen, Zhang \& Vogel, 2011; Fletcher, Bailey \& Gilman, 2017; Ganjali \& Rezaee, 2016; Geldenhuys, Taba \& Venter, 2014; Gloria \& Steinhardt, 2016; Soane, Shantz, Alfes, Truss, Rees \& Gatenby, 2013). 
A second stream of research that builds on the job characteristics model derives from Spreitzer's (1995) research on psychological empowerment (e.g. Chen et al., 2011; Li et al., 2008; Montani, Boudrias \& Pigeon, 2017). Psychological empowerment is defined as a multi-faceted construct comprising: 'a set of four cognitions reflecting an individual's orientation to his or her work role: meaning, competence ... self-determination, and impact' (p. 1443). In this context, meaningfulness is taken to be "the value of a work goal or purpose, judged in relation to an individual's own ideals or standards' (p. 1443).

These two strands of research have subsequently been combined; May, Gilson and Harter (2004) added Spreitzer's (1995) measure of meaningfulness to other items and developed a new six-item scale which they used in their study of personal role engagement, and which has also been used in an abbreviated four-item version (e.g. Soane et al., 2013). This approach does not distinguish between different facets or dimensions of meaningfulness.

Meaningfulness within the workplace spirituality literature: A number of researchers have used the theoretical work of Ashmos and Duchon (2000) in the domain of workplace spirituality to conceptualize meaningfulness. Scholars in this tradition have recognized 'that employees have an inner life that nourishes and is nourished by meaningful work that takes place in the context of community' (Duchon \& Plowman, 2005, p. 809). The workplace spirituality approach suggests that organizations can enable human flourishing by providing a setting in which the spiritual needs of an inner life, meaningful work and community can be met (Ahmad \& Omar, 2016; Albuquerque, Cunha, Martins \& Sa, 2014; Daniel, 2015). As one element of this, meaningful work encompasses 'cognitively meaningful tasks, but it is also about work that creates a sense of 
joy, which connects workers to a larger good and to things viewed by the worker as important in life' (Duchon \& Plowman, 2005, p. 814). The Meaning and Purpose at Work Scale developed by Ashmos and Duchon (2000) has been quite widely used in the literature thus far (e.g. Arnold, Turner, Barling, Kelloway \& McKee, 2007; Pradhan \& Pradhan, 2016). The scale captures meaningful work in the sense of the experience of joy by self and other, energizing work, and the connection between work and the wider good. This approach suggests that meaningfulness is multi-dimensional by extending beyond a focus on self-fulfillment to argue that meaningfulness arises when work contributes to the wider good. This resonates with theoretical and conceptual arguments proposed within the HRD field concerning the role that learning and development can play in fostering a sense of meaning and purpose among employees within the wider context of a workplace spirituality approach (Dirkx, 2001; 2013). Such approaches place emphasis on the growing salience of humanistic work environments that enable employees to bring their soul to work, and take into consideration the deeper levels of human experience (Adawiyah \& Pramuka, 2017; Khan \& Sheikh, 2012).

Meaningfulness within the humanities tradition: Another way that meaningfulness has been conceptualized derives from the humanities field, based on theorists such as Jung or Frankl, to argue that meaning-making is a fundamental human characteristic (e.g. Bunderson \& Thompson, 2009; Lips-Wiersma \& Morris, 2009; Lips-Wiersma \& Wright, 2012; Lips-Wiersma, Wright \& Dik, 2016; Thory, 2016). Within the context of the natural human impetus to seek a meaningful life, or the 'will to meaning' (Lips-Wiersma \& Morris, 2009, p. 492), meaningful work is regarded as having a central role to play in the perception of life overall as meaningful. It is within this research tradition that we can discern the closest connection to theoretical writings on the topic of meaningfulness within the fields of political theory, philosophy, business ethics and 
theology (e.g. Bowie, 1998; Ciulla, 2012; Michaelson, 2009; Tablan, 2015; Wolf, 2010; Yeoman, 2014). Here, although viewpoints are divergent, meaningful work is generally regarded as a social, political, ethical and moral issue (May, Li, Mencl \& Huang, 2014). Some within this tradition have argued that meaningful work comprises both objective features, in that it enables autonomy, freedom and social recognition, as well as being subjectively experienced as meaningful by the individual (Wolf, 2010; Yeoman, 2014). Scholars within the humanities have proposed that the greatest sense of meaningfulness arises from coherence across four domains: unity with others, expressing oneself, serving others and developing and becoming oneself (e.g. Lips-Wiersma \& Morris, 2009; Lips Wiersma et al., 2016). Studies have mostly adopted qualitative and inductive approaches such as action research or interview-based studies that generate an understanding of meaningfulness from the individual's perspective (eg LipsWiersma, 2002). The second way meaningful work is understood within the humanities tradition is as 'fulfilling, significant, directed, coherent with life goals, and contributing to a sense of belonging' (Schnell, Hoege \& Pollet, 2013, p. 548).

A crucial difference between this research strand and the others is that it is founded on the premise that the quest for meaningfulness is inherent: 'it is a condition of being human to make meaning', rather than something that 'can be supplied' by an organization, its leaders or through job design initiatives (Lips-Wiersma \& Morris, 2009, p. 503-4). However, the measures used to operationalize meaningful work have focused exclusively on capturing the subjective experience of meaningfulness and have not sought to evaluate work's objective features. In this sense, the empirical research conducted within the humanities tradition departs from much of the theorizing that has taken place within this field (e.g. Wolf, 2010; Yeoman, 2014). 
Meaningfulness as a multi-faceted eudaimonic psychological state: A third perspective has drawn from both the positive psychology, as well as the spirituality and humanities perspectives and has branched into two approaches. The first of these has followed the work of Steger, Dik and Duffy $(2012 ; 2013)$ who argued meaningful work is a eudaimonic psychological state comprising three facets: the subjective sense of positive meaning individuals derive from their work; the link between meaningfulness in work and in the individual's wider life; and the desire to make a positive impact or contribute to the greater good (Bergmann, Renshaw, Allen, Markman \& Stanley, 2014; Rasmussen, Turnell, Butow, et al., 2016; Steger et al., 2012; 2013). Here, the evaluation of work as meaningful refers to individuals' judgment that their work is significant, worthwhile, and has positive meaning (Tims, Derks \& Bakker, 2016). Scholars have used the 10-facet Work and Meaning Inventory (WAMI; Steger et al., 2012), which is the most widely adopted meaningful work scale among the papers we reviewed. The scale comprises 10 items with sub-scales capturing three dimensions (Positive Meaning, Meaning Making through Work and Greater Good Motivation). This scale was reviewed by Both-Nwabuwe et al. (2017) and found to have strong psychometric properties. Research within this tradition has drawn on theories of pro-social behavior in explaining the greater good motivations associated with meaningful work (e.g. Grant, 2007).

The second approach under this heading has its basis in the work of Bunderson and Thompson (2009) who did not provide a clear definition of meaningful work, but who rather linked the construct with the notion of callings, and suggested that those who perceive their work as a calling are more inclined to find it meaningful. They proposed a somewhat narrower conceptualization of meaningfulness than Steger et al. (2012), comprising a five-item measure with two core features: work that is important and meaningful to the individual, and work that 
makes a difference to the world. Their approach has been adopted in several other studies (e.g. Chen, Lee, Chen \& Wu, 2016; Hirschi, 2012).

Meaningfulness as an occupation-specific phenomenon: In our review, we identified some studies which explored meaningfulness within the context of particular occupations and which have correspondingly developed bespoke definitions that are relevant to those occupational contexts but which are not necessarily transferable to other occupations. For example, Britt, Adler and Bartone (2001) and Britt, Dickinson, Castro and Adler (2007) examined meaningfulness in the context of military work and defined and measured it as a combination of being engaged in important work during the course of military operations and experiencing events during the course of deployment that set the deployment in a broader context. McCarthy and Friedman (2006) focused on meaningful work in the context of a nursing home, defining it as 'acts that lead to a sense of achievement and interaction with residents' (p. 58). These studies raise important questions about the comparability of the experience of meaningfulness across occupational groups.

Other definitions and conceptualizations: Beyond the more widely adopted definitions outlined above, there were a number of studies that used independent definitions of meaningful work. For example, Cohen-Meitar, Carmeli and Waldman (2009) suggested that meaningfulness arises when one's personal identity is integrated with one's role in the organization. For Scroggins (2008), meaningfulness arises when there is consistency between an individual's self-perception and their actual work role. 


\section{Results: Theories of Meaningful Work}

Given the disparate range of definitions, it is unsurprising that a similarly extensive range of theoretical frameworks had been used. In many of the studies, however, it was difficult to discern a specific theoretical framework that was relied upon to explain the construct of meaningful work itself, or how it related to other constructs. In such cases, where possible, we have inferred the theoretical intentions of the authors on careful reading of each article. By far the largest number of studies can be classified as located within work/industrial/organizational psychology, where meaningfulness is broadly considered as a motivational attitude or perception that is likely to be influenced by a range of personality factors and, equally, is malleable according to factors within the workplace, such as workplace relationships, supervisory support, or job design features. In consequence, the majority of theoretical frameworks used in the meaningful work literature emanate from positive psychology and adopt a line of argument similar to those used in related topic areas, such as work engagement (Bailey, Madden, Alfes \& Fletcher, 2015).

The psychological theory that was most extensively referenced was Hackman and Oldham's $(1975 ; 1976)$ job characteristics model, which situated the experienced meaningfulness of work as one of the individual psychological states arising from features of job design, in particular task significance (e.g. Johns et al., 1992; May et al., 2004). Transformational leadership theory was the second most widely used (e.g. Arnold et al., 2007; Ghadi, Fernando \& Caputi, 2013) as a means of explaining how levels of meaningfulness can be raised among followers, along with a range of theories of intrinsic motivation (e.g. Chen et al., 2016; Gloria \& Steinhardt, 2016). However, we found evidence of the use of a very broad array of psychological theories, the majority of which were only referred to once or twice, including social identity theory (Cohen- 
Meitar et al., 2009), broaden and build theory (Soane et al., 2013), social learning theory (Miller \& Wheeler, 1992), social exchange theory (Rafferty \& Restubog, 2011) and the job demandsresources framework (Steger et al., 2013). In the majority of these studies, meaningful work was situated as an antecedent factor or as a mediating factor within a wider model of workplace attitudes and outcomes, and hence frameworks were derived from theories commonly used in other topic areas within positive psychology, such as leader-member exchange theory (Tummers \& Knies 2013), or personal role engagement theory (Kahn, 1990). A very small number of studies was grounded in specific sub-fields of psychology such as family psychology (e.g. Bergmann et al., 2014) or humanistic psychology (e.g. Isaksen, 2000).

The second most widely adopted framing of meaningful work was situated within the literature on spirituality or callings (e.g. Ahmed \& Omar, 2016; Albuquerque et al., 2014). Here, meaningful work was generally regarded as one element of spirituality at work alongside others, such as inner life, belonging and purpose. This line of research aligns most closely with the strand of writing within the HRD field on workplace spirituality in the context of holistic human development (Dirkx, 2001; 2013). Writers also drew on frameworks and theories from the humanities literature in terms of explaining the wider ontological significance of meaningful work (e.g. Lips-Wiersma, 2002; Lips-Wiersma \& Morris, 2009), but many studies under this heading applied these constructs within positivist models more commonly used in the psychology field (e.g. Bunderson \& Thompson, 2009; Duffy, Allan, Autin \& Bott 2013; Duffy, Blake, Autin \& Douglass, 2014; Gupta, Kumar \& Singh, 2014). A very small body of research on meaningful work has been conducted within the occupational health field, and has explored the associations between meaningfulness and markers of psychological health or distress such as morale, wellbeing or stress (e.g. Britt et al., 2007; Leiter \& Harvie, 1997; Torp, Vinke \& HaaheimSimonsen, 2017). 


\section{Results: The Outcomes of Meaningful Work}

A total of 52 studies examined the outcomes of meaningful work, and these can be organized under six headings.

Work-related attitudinal and behavioral outcomes: Most often, researchers considered a range of work-related attitudinal outcomes, especially pertaining to work or personal engagement (Fletcher et al., 2017; Geldenhuys et al., 2014; Gloria \& Steinhardt, 2016; Johnson \& Jiang, 2016), job satisfaction (Duffy et al., 2013), organizational commitment (Leiter \& Harvie, 1997), behavioral involvement (Montani et al., 2017), and intrinsic motivation (Johns et al., 1992). All these studies found that meaningful work was positively associated with these outcomes. Other outcomes at the individual level that have been explored in a smaller number of studies, with similarly positive results, include: affective commitment, job enjoyment, job security, intrinsic reward, feelings of accomplishment or growth, positive self-concept, organizational identification, morale, perceived benefits of military deployment, career commitment, turnover and motivation (e.g. Britt et al., 2001; Chen \& Li, 2013; Fairlie, 2011; Gupta et al., 2014; Hackman \& Oldham, 1976). Only two studies found no significant link between meaningful work and positive attitudinal outcomes; these were studies of environmental mastery, autonomy and positive relations with others (Bassi et al., 2013; although meaningfulness was measured by a single item) and extrinsic motivation (Lips-Wiersma \& Wright, 2012).

Articles that were focused on links between meaningful work and absence or turnover intentions indicated that meaningful work was associated with low levels of intention to quit (e.g. Fairlie, 
2011). Meanwhile, investigating staff absence and employee engagement, Soane et al. (2013) found a negative link between meaningful work and absence levels. However, Miller and Wheeler (1992) showed that while the association between meaningful work and turnover cognitions held for women, this was not the case for men.

Performance-related outcomes: Researchers have focused on a range of performance-related outcomes. One study in the healthcare sector, for example, used performance data obtained from regional health authorities to examine the association between meaningful work and organizational performance (Albuquerque et al., 2014). Although the researchers failed to establish this link, they did find meaningful work to be associated with perceived patient satisfaction and 'perceived just-in-time' management. A positive association between meaningful work and patient satisfaction was also found in one other study (Duchon \& Plowman, 2005).

Meaningful work has been linked with perceived organizational reputation (Leiter \& Harvie, 1997), knowledge sharing (Chen et al., 2011), individual-level performance perceptions (Pavlish \& Hunt, 2012), organizational citizenship behavior (Chen \& Li, 2013), and creativity (CohenMeitar et al., 2009). For example, Ganjali and Rezaee (2016) showed that a positive association between employee voice and meaningful work contributed to intrinsic motivation and creativity. In a study using employee-supervisor dyads, Rafferty and Restubog (2011) found meaningful work to be linked to prosocial silence, or the withholding of work-related ideas for the benefit of the organization. Overall, only a relatively small number of studies focused specifically on the performance outcomes of meaningful work, but some of these drew on multi-level data so provide strong evidence of a link (e.g. Duchon \& Plowman, 2005). 
Existential outcomes: Research has also examined what can be termed existential outcomes, which are associated with the effects of meaningful work upon life as a whole, including impacts upon personal identity formation. Positive associations were found between meaningful work and outcomes such as life meaning, life satisfaction, work as enabling the self, work as a calling and work-life enrichment (Allan, Autin \& Duffy, 2016a; Johnson \& Jiang, 2016; Lips-Wiersma \& Wright, 2012; Mather, 2008), aligning with debates in the HRD field (Chalofsky, 2010). In one qualitative study, conducted in the healthcare sector, Pavlish and Hunt (2012) for instance found meaningful work to be linked with feelings of accomplishment, growth, happiness and blessings. Meanwhile, in a longitudinal study by Duffy et al. (2014), meaningful work was found to be associated with living a calling. Bassi et al.'s (2013) research did not find meaningful work to be associated with self-acceptance or purpose in life. However, Steger et al. (2012) equally did not find meaningful work to be associated with individuals' search for meaning, which suggests that more research is needed in this area. A small number of studies have examined the link between meaningful work and outcomes at the work-life interface. These have shown a link between meaningful work, work-to-family enrichment (Tummers \& Knies, 2013), and reduced levels of work-life interference (McCrea, Boreham \& Ferguson, 2011). Two of the studies included samples from the military: Bergmann et al. (2014) revealed mediated associations involving meaningful work and marital satisfaction for both service members and spouses, and Britt et al. (2001) found meaningful work to be associated with post-deployment benefits by using a time lagged survey of soldiers on active military deployment and five months after returning home.

Wellbeing: Researchers have found that meaningful work was positively linked to outcomes such as wellbeing (Littman-Ovadia \& Steger, 2010; Pollet \& Schnell, 2016), or reduced levels of stress and depression (Daniel, 2015). One study, however, failed to establish a link between 
meaningful work and reduced levels of anxiety (Steger et al., 2012). Overall, the research on wellbeing outcomes is sparse.

\section{Results: Organizational Practices/Antecedents Associated with Meaningful Work}

The experience of meaningfulness in work and the associated outcomes may be conditioned by a wide range of organizational practices and antecedents. Additionally, meaningful work has frequently been incorporated into psychological or organizational studies as a moderator to explain individual and organizational level effects. Across the literature, four groups of antecedent factors of meaningful work were identified.

Job design: From the studies that considered aspects of job design, some applied Hackman and Oldham's (1975) job characteristics model and found that skill variety, task significance and task identity were associated positively with meaningful work (e.g. Johns et al., 19921; Schnell et al., 2013). Similarly, Bailey and Madden (2016) found that employees' perception of their work tasks as pointless contributed to a sense of meaninglessness. Work-role fit or self-concept fit has been found to be relevant for meaningful work by May et al. (2004), who also established a link between job enrichment and meaningful work. Kahn (1990), in his ethnographic study, found an association between a range of task and role characteristics and meaningful work including challenging, creative, autonomous work that conferred status and influence on the role holder. Although Chen et al. (2001)'s research showed no link between perceived task conflict and meaningful work, Fletcher et al. (2017) found evidence of an association between task clarity, access to resources and meaningful work, suggesting some ambiguity about the nature of the link between certain aspects of job design and meaningfulness. Overall, most research considering the 
antecedents of meaningful work has focused on job design and so the evidence base for this is strongest.

Leadership and management: Studies focusing on leadership and management have generally found positive associations between meaningful work and leadership styles such as transformational leadership (Arnold et al., 2007; Ghadi et al., 2013; Pradhan \& Pradhan, 2016), leader sense-giving (Carton, 2017), strong leader-member exchange (Tummers \& Knies, 2013), spiritual leadership (Duchon \& Plowman, 2005), or supervisor support (Gloria \& Steinhardt, 2016). Participative and constructive management styles have also been associated with higher levels of meaningful work (McCrea et al., 2011; Pavlish \& Hunt, 2012). There is also a small body of research that has linked abusive or divisive supervision with reduced meaningfulness (Bailey \& Madden, 2016; Pavlish \& Hunt, 2012; Rafferty \& Restubog, 2011).

Organizational level factors: A few studies have focused on factors at the organizational level. Broadly, research has shown that spiritual (Duchon \& Plowman, 2005), or learning-focused (Pavlish \& Hunt, 2012) work climates are linked with meaningful work. Schnell et al. (2013) found levels of meaningful work to be associated with socio-moral organizational climate and organizational self-transcendent orientation. Finally, Albuquerque et al. (2014) compared reports of meaningful work in two types of healthcare setting and found levels to be higher in the setting characterized by autonomy, self-selected teams and a community orientation, although these factors were not specifically measured in the study. Conversely, Bassi et al. (2013) compared a thriving versus failing organization and found no difference between situational uncertainty levels in these two settings and levels of meaningful work although, again, the single-item measure used means that this conclusion should be regarded as tentative. 
Workplace relationships: Positive workplace relationships have been found to be important for meaningful work (e.g. Bailey \& Madden, 2016; Chen et al., 2011; Isaksen, 2000; Kahn, 1990). Further, Montani et al. (2017) showed a positive link between manager recognition and meaningful work, moderated by co-worker recognition. Colbert, Bono \& Purvanova (2016, p. 1215) argued that meaningful work needs to be considered against 'an increasing reliance on relational means of organizing and increasingly porous work-life boundaries [which] set the stage for work relationships to serve a broader range of functions than in the past'. Such links between meaningful work and wider forms of meaningfulness and the self have been explored in other studies, such as those by Lips-Wiersma and Morris (2009) and Lips-Wiersma (2002), who found that unity with others and serving others represented two important constitutive dimensions of meaningful work. Meanwhile, Munn's (2013) study showed a positive link between work-life fit (in the sense of a supportive work-life culture) and meaningful work, as well as a negative association between work-life conflict, or a perceived imbalance between work and personal life, and meaningful work.

\section{Results: Individual Characteristics Associated with Meaningful Work}

Some studies have also considered the salience of a range of individual-level factors for meaningful work. However, fewer studies have been conducted that focus on the individual-level antecedents of meaningful work than have focused on the organizational-level factors that create the setting within which meaningfulness might be experienced. Consequently, there are some important gaps in our knowledge and understanding of how and why some individuals might find their work more or less meaningful than others. 
Antecedents: With respect to antecedents, Britt et al.'s (2001) study of military personnel found a link between soldier hardiness and perceived meaning in work, while Bergmann et al.'s (2014) research in the military showed that when stressful events give rise to post-traumatic stress disorder (PTSD) there was a negative association for soldiers (and their spouses) with their perception that their work was meaningful. Other research has demonstrated that personal character strengths and the ability to deploy them (Littman-Ovadia \& Steger, 2010, study 2) and living a calling (Duffy et al., 2013) were associated with meaningful work. Only one study, by Allan et al. (2016a), addressed social class as a factor (measured by subjective social status) which was found to positively predict a-motivation ('absence of intention to act') and lower levels of meaningful work. Weeks and Schaffert (2017) examined the potential for generational differences in sources of meaningfulness using Lips-Wiersma and Morris's (2009) model, but found broad similarities in terms of how meaningfulness is experienced.

Moderators and Mediators: With respect to moderation effects, Soane et al. (2013) found that individual levels of wellbeing significantly moderated the relationship between meaningful work and employee engagement. Meanwhile, both Hackman and Oldham (1976) and Johns et al. (1992) found that links between job characteristics and positive organizational and individual outcomes were mediated by experienced meaningfulness and moderated by differences in the need to grow in one's job (growth need strength). Gloria and Steinhardt's (2016) research found that positive emotions mediated the link between meaningful work and engagement. Research in Taiwan showed that individual pro-social motivations partially mediated the relationship between task significance/external prestige and meaningful work (Chen et al., 2016).

Associations: Compared with moderation or mediation, associations between individual differences and meaningful work were a more common finding. Occupation type emerged as 
significant in two studies. First, Albuquerque et al. (2014) showed that doctors and nurses found their work more meaningful than administrative staff. Second, in a qualitative study of nurses, Pavlish and Hunt (2012) found that job role perceptions were linked with perceived meaningfulness. However, a further qualitative study of catering staff found individual abilities to construct meaning were more important than occupational role (Isaksen 2000). Treadgold (1999), also using a qualitative approach, found that having a clear self-concept and individual coping style were correlated with engagement in meaningful work. Finally, in a three-wave study, Tims et al. (2016, p. 45) found that job crafting behaviors, or 'changes employees make in their job on their own initiative' were positively related to person-job fit and to meaningful work.

\section{Discussion and Implications for HRD}

In reviewing the empirical evidence base for meaningful work, it was surprising that not more studies met our inclusion criteria. We deliberately cast a wide net but, had we been more stringent, for instance, by excluding studies containing one-dimensional measures of meaningfulness or by excluding cross-sectional self-report studies, then volume of research would have been considerably reduced. The empirical literature on meaningful work is experiencing a complex evolution, relying on concepts and theories drawn from psychology, workplace spirituality and the humanities. These various strands have been mutually influential, leading to the development of a plethora of definitions and measures, all of which regard meaningful work as a positive, subjective, individual experience. There is a significant body of 
research evidence in which meaningful work is defined simply as work that is subjectively meaningful, important, rewarding, or aligned with personal values (e.g. Montani et al., 2017; Nair \& Vohra, 2010; Renard \& Sneglar, 2016). Confusingly, there is also research which defines meaningful work in very different ways, for example as purposeful work (Arnold et al., 2007), or as the congruence between the individual's job and personal beliefs (e.g. Li, Chen \& Kuo, 2008). Some researchers have also defined meaningful work as specific to particular occupational groups (e.g. Britt et al., 2001; 2007; McCarthy \& Friedman, 2006). Approaches such as these suggest that there is at present no consensus over how to define meaningful work.

In light of the shortcomings of extant approaches, the most influential contemporary researchers have argued for the inclusion of a range of dimensions as core to the experience of meaningfulness (e.g. Duchon \& Plowman, 2005; Lips-Wiersma, 2002; May et al., 2004; Steger et al., 2012). The most comprehensive models comprise an integrative framework incorporating elements of self-oriented experiences, such as developing the inner self or self-expression, alongside other-oriented experiences, such as belonging and service (Lips-Wiersma \& Morris, 2009; Rosso et al., 2010).

The complexity of the field is further supported by our observation that, out of 56 articles adopting quantitative methods, there were 28 different measurement scales in use, (plus shortened variations), the majority of which were only used in one or two studies. The number of items in the scales ranged from 1-53 and the number of facets or sub-scales varied between one and eight. Most measures were used three times or fewer, although Both-Nwabuwe et al. (2017) cited the recently-developed Comprehensive Meaningful Work Scale (Lips-Wiersma et al., 2016) as both valid and reliable, suggesting the potential for the adoption of this measure in future 
research. Although virtually all the scales measured meaningfulness as a positive attribute, Tummers and Knies (2013) reverse-scored the Mottaz (1981) work alienation scale, thus conceptualizing meaningfulness as the opposite of alienation. Insufficient research has been conducted to evaluate whether this is the case, or whether these are separate constructs. The existence of a large number of single-item measures of meaningfulness, and the widespread use of instruments that evaluate meaningfulness as comprising a single facet, indicate that quantitative researchers are not yet clear over whether meaningfulness does in fact constitute a higher-order factor comprising a number of facets.

The weight of evidence we reviewed suggests that employees are more likely to experience meaningfulness when they connect to diverse sources of meaningfulness rather than simply one (Rosso et al., 2010; Schnell et al., 2013). Lips-Wiersma and Wright (2012) described how meaningfulness arises from 'dynamic processes of seeking wholeness through addressing the relationship between multiple sources of meaning' (p. 658). However, uncertainty remains over which dimensions of meaningfulness should be included and which are most salient, as well as the nature and direction of their integrative effects. Researchers have also yet to address the question of whether one type of meaningfulness may serve to off-set a deficiency in another, how frequently meaningfulness needs to be experienced in order for the individual to regard their work overall as meaningful, and whether it is possible to have too much meaningfulness. Thus, meaningfulness emerges as an 'essentially contested concept' (Gallie, 1956), likely to produce further debate and variation as scholars expand their conceptual understanding and accumulate new evidence. 
A related consideration is that the empirical literature remains focused entirely on meaningful work as a subjective experience. However, longstanding debates within political theory suggest that meaningfulness may equally have objective dimensions. For example, Yeoman (2014) argued that work can only be meaningful when it is structured as jobs which offer freedom, autonomy and dignity as a 'moral and political project' (Yeoman 2014, p. 236). Although some empirical studies of meaningful work have made reference to the notion of the significance or worthwhile nature of the work undertaken (e.g. Hackman \& Oldham, 1975; Steger, Frazier, Oishi \& Kaler, 2006), links have not been made to notions of objectively-defined 'morally worthy work in a morally worthy organization' (Ciulla, 2000). Thus, there are important gaps in our understanding of how meaningfulness is shaped by the wider political, societal and institutional context, as well as how diversity, power and resistance may be implicated in the experience of meaningfulness.

Although much of the literature does not directly address the processes by which work is rendered meaningful to the individual, there is an emerging interest in constructivist accounts which examine meaningful work using sense-making and interpretivist approaches (Schnell et al., 2013). This has surfaced neglected aspects of meaningful work such as connection-building (Carton, 2017). Thus, there is a small but growing body of evidence that engages with the integrative processes through which individuals construct a sense of their work as being meaningful (Steger et al., 2012). However, this literature is not yet sufficiently developed to enable conclusions to be drawn.

Despite the fact that meaningfulness is viewed almost uniformly within empirical studies as a positive construct, there is a small body of work that highlights the tensions and conflicts inherent 
in meaningful work. For example, some scholars have suggested that a sense of meaningfulness may arise through the process of confronting poignant, controversial or challenging situations that cause the individual to re-appraise what is important to them (Bailey \& Madden, 2016; Chen et al., 2011; Mitra \& Buzzanell, 2017). Lips-Wiersma and Wright (2012) found that tensions are unavoidable in the search for meaning, and that these tensions are manifest most often in efforts to integrate the opposing dimensions of doing/being and self/other. Studies such as these point to the complex, ambivalent and demanding processes that may be connected to meaningfulness and highlight a gap in our understanding of the experience of meaningful work.

Given these findings, what can be said about the evidence base thus far for meaningful work? Empirical research on meaningful work has followed an interesting trajectory through time, starting with Hackman and Oldham's (1976) job design studies. The next publications did not emerge until a small number of studies that took place in the 1990s; several of these lacked underpinning theoretical frameworks or conceptualizations of meaningful work, but some developed Hackman and Oldham's work further, for example, exploring the link between meaningfulness and engagement (Kahn, 1990). The second important strand of research has located meaningful work within the context of workplace spirituality, and this can largely be traced back to the work of Ashmos and Duchon (2000) and the growing interest in aspects of spirituality at work such as spiritual leadership, spiritual work climates, callings, and existential attitudes towards work. This has been particularly influential within the conceptual literature in the HRD field (eg Adawiyah and Pramuka, 2017; Dirkx, 2001; 2013). A third strand has seen the application of concepts from the humanities developed originally to explain the broader notion of meaningfulness in life to meaningful work, notably the work of thinkers such as Jung and Frankl. This has been particularly evident in research by Lips-Wiersma (e.g. Lips-Wiersma \& Morris, 
2009). However, the number of studies adopting this approach is small, and further research would be welcome. By far the most significant body of empirical work on meaningfulness in recent years has adopted a positivistic, quantitative approach and falls broadly within the positive psychology literature (eg Ahmad \& Omar, 2016; May et al., 2004; Tims et al., 2016). Here, researchers have been concerned with precise definitions and the development of valid and reliable psychometric scales to measure meaningfulness in the context of wider models of positive psychology.

With regard to the weight of evidence, there are several studies using complex methods that show meaningful work to be associated with other positive attitudes such as engagement, satisfaction, and commitment (e.g. Albuquerque et al., 2014; Fletcher et al., 2017; Kahn, 1990). Studies such as these which draw on longitudinal data, observation, or data from different sources can be more reliable than cross-sectional research. There is also some evidence suggesting that meaningful work is more likely to arise for individuals employed in work settings characterized by welldesigned jobs and led by transformational or spiritual leaders (e.g. Duchon \& Plowman, 2005; Rafferty \& Restubog, 2011). Equally, qualitative research suggests that the experience of meaningfulness is characterized by the dynamic inter-relationship between positive work experiences of importance to the individual, their sense of belonging, and their wider role and contribution (e.g. Bailey \& Madden, 2016; Lips-Wiersma \& Morris, 2009; Pavlish \& Hunt, 2012). High levels of meaningfulness have been associated in complex studies with outcomes such as reduced levels of absenteeism (Soane et al., 2013), patient satisfaction (Albuquerque et al., 2014), and engagement (Chen et al., 2011), confirming the role of meaningfulness as a positive psychological state. Nevertheless, important gaps remain in the knowledge base surrounding the antecedents and outcomes of meaningful work. 


\section{Implications for HRD Theory}

This analysis of the empirical evidence on meaningful work makes a number of theoretical contributions to the HRD literature. First, the study has brought to light widely divergent viewpoints over the conceptual terrain of meaningful work which suggests that there is scope for HRD scholars to foster definitional creativity by bringing the empirical evidence together with the broader conceptual and theoretical literature on meaningfulness within HRD. To date, most advances in understanding meaningful work within HRD have taken place at a conceptual level and have primarily emphasized the spirituality approach (eg Chalofsky, 2003; Cullen, 2013; Daniel, 2010; Dirkx, 2001; 2013), with just a small number of empirical studies having taken place in the HRD field (eg Fairlie, 2011; Munn, 2013; Thory, 2016). HRD scholars could draw on empirical insights from the wider research base to explore alternative perspectives on meaningfulness, for example those deriving from the humanities literature and the work of Frankl (eg Lips-Wiersma and Morris, 2012) or from the psychological empowerment field (eg Colbert et al., 2016) to explore how these might enrich knowledge from an HRD perspective.

Thus far, the HRD community has embraced a subjective conceptualization of meaningfulness as work that is perceived by the individual to be meaningful to them as individuals (eg Chalofsky, 2010). However, literature in the field of political theory suggests that meaningfulness comprises not just subjective but also objective dimensions, notably as work that enables individual autonomy, dignity and freedom (Yeoman, 2014). Empirical studies that address some of the fundamental issues concerning the association between subjective and objective dimensions of meaningfulness would expand research within the HRD domain and link to research interests 
around job quality. For example, can jobs that objectively lack meaningfulness be perceived as meaningful by the individual?

From the perspective of quantitative researchers, the analysis has revealed a wide range of scales that can be used to measure levels of meaningfulness within the context of broader attitudinal surveys. For HRD scholars interested in evaluating the association between meaningfulness and other important HRD variables such as perceptions of learning and development quality, organizational culture, job design, work-life balance or careers, as well as a range of outcomes, there is an opportunity to explore the validity and reliability of these measures and evaluate from a quantitative perspective the extent to which HRD interventions are salient for employees' experience of meaningfulness. Alongside this, there is a need for the development of more robust measures that capture meaningful work in a way that enables a growing bank of knowledge on the topic relevant to the HRD community to accumulate (Both-Nwabuwe et al., 2017). For example, researchers could undertake studies that compare the predictive power of the extant measures, and also examine the relative significance of the various facets of meaningfulness that have been proposed.

The findings of the research lend weight to the arguments of those scholars within the HRD community who approach meaningful work from a spirituality perspective. For example, studies have shown a link between spiritual leadership (Chen \& Li, 2013) or spiritual work climates (Duchon \& Plowman, 2005) and meaningfulness. However, the empirical evidence remains relatively sparse and there is scope for further research in this area. For example, HRD researchers could build on the work of Dirkx (2013) and Thory (2016) to explore more deeply how work-related learning enables individuals to uncover a personal sense of meaning and 
purpose through their work. As Dirkx (1997, p. 79) noted, many approaches to learning are still founded within a 'technical-rational view of knowledge' and fail to take account of individuals' search for meaning. Transformative learning, or 'learning through soul' (ibid, p. 80) represents an important dimension of learning that is often ignored, and so research that addresses this more holistic approach to learning would be beneficial. Learning and development may have a particularly important role to play in fostering work cultures and leadership styles that enable a sense of meaningfulness to emerge (Chalofsky, 2010), and there is scope for further research within HRD that develops this strand of the literature to explore for example what types of leadership development interventions are most effective in enhancing leaders' capability to foster meaningfulness among followers.

The present analysis has uncovered the weight of evidence relating to the salience of job design factors such as job enrichment, work-role fit, job content and task characteristics for meaningful work. This lends support to the propositions of HRD scholars such as Chalofsky (2010) and Garg and Rastogi (2006) who argued that individuals strive for a sense of meaning, purpose and community at work, and that designing jobs that enable employees to draw on these to experience a sense of meaningfulness will lead to enhanced job satisfaction, motivation and performance. Further research investigating the relative importance of different features of job design for meaningfulness would enable HRD scholars to gain a more nuanced understanding of how the link between job design and meaningfulness works.

Within the HRD literature, there have been calls for further research on the link between meaningfulness and career behavior (Cullen, 2013). However, our analysis found that only one empirical study has so far addressed this; Lips-Wiersma (2002) identified four facets of 
meaningful work - developing and becoming self, unity with others, expressing self and serving others - which were found to influence career behavior. Given that Cullen (2013) argued that a constructionist approach to vocational ideation enables individuals to enhance self-awareness through a more holistic understanding of their personal identity and how meaning is coconstructed through relationships, it would seem that there is significant scope for further research within HRD that explores how meaningfulness can influence career behavior.

We uncovered associations between the experience of meaningfulness and a range of outcomes salient for the HRD community, including high levels of engagement, job satisfaction, intrinsic motivation, commitment, wellbeing and performance, and low levels of absence and turnover. Overall, when individuals found their work meaningful, they were more likely to experience positive outcomes. This resonates with conceptual contributions to the HRD literature focusing on the positive individual and organizational outcomes of meaningfulness (Chalofsky, 2003; Dirkx, 2013).

However, Thory (2016) found that increased awareness of meaningfulness could also lead to tensions between people's sense of their ideal job and reality and between the need for short-term deliverables and unity/community at work, as well as to detrimental health outcomes for those overly focused on others. Thory also noted that not everyone desires meaningful work, and that the outcomes of meaningfulness were not necessarily always positive for the employer. Findings such as these within HRD raise questions about the uniform desirability of meaningful work, and moreover point towards a potential 'dark side' of meaningfulness similar to studies at the intersection between callings and meaningful work which found individuals were prepared to endure significant hardships in pursuit of their calling (e.g. Bunderson \& Thompson 2009). 
Research has also suggested that finding meaningfulness in work may be effortful, challenging or difficult (e.g. Bailey \& Madden, 2016; Lips-Wiersma \& Wright, 2012). Further empirical inquiry into the potentially harmful or troubling effects of meaningful work, and into whether meaningfulness is in fact a desirable experience for all, may reveal further insights into the tradeoffs and tensions involved.

The analysis also showed that there is a need for more studies that examine meaningful work in a cross-national context since most extant research has taken place in North America with a scattering of other studies around the world. This is important for the international HRD community. Thus far, these studies have not addressed important questions around the crossnational comparability of the meaningful work construct, or whether different antecedents are more or less important in different national settings. It could be conjectured, for instance, that notions of meaningfulness may vary across cultural or religious communities and studies could explore this proposition. Only one study by Woodard, Miller, Miller, Silvernail, Guo, Nair \& Peters (2016), has attempted to consider cross-cultural differences in meaningful work using notions of collectivism versus individualism. However, as the authors themselves pointed out, their findings were limited by insufficient sample sizes to draw reliable conclusions.

Research to date has not examined in depth the experience of meaningfulness within different occupational groups. Some progress has been made in a recent study by Lips-Wiersma et al. (2016) which found some variation between white, pink and blue-collar workers in their experience of meaningful work. Another study examined meaningfulness in individual sectors (Albuquerque et al., 2014). However, there have only been two studies attempting to explore whether, for instance, there are differences between the experience of meaningfulness for 
workers in stigmatized, professional or caring occupations which might present divergent opportunities to find work meaningful (Bailey \& Madden, 2016; Lips-Wiersma et al., 2016). Linked to this is also a relative paucity of research explicitly addressing individual differences such as age, gender or personality in relation to meaningful work, and further research on these topics would also be welcome and provide an important contribution to HRD.

Finally, as was highlighted earlier, there remains some confusion between the 'meaning of' work and 'meaningful' work. Rosso et al. (2010: 94) suggested that "meaning" is "the output of having made sense of something", which can potentially yield a wide range of meanings both positive and negative. Meaningful work, though, was defined by Chalofsky (2010, p. 19) as 'an inclusive state of being' associated with intrinsic motivation that is the opposite of alienation. There is a small body of research within HRD concerned with the 'meaning of' work (eg Kuchinke et al., 2009; McLure \& Brown, 2008; Sharabi \& Harpaz, 2010). Studies such as these have shed light on issues such as work centrality and the comparative meaning of work across cultural settings. Furthermore, the "meaning of work" extends to debates about the social value of work as a human activity, and the centrality of work as part of the good life (Brief \& Nord, 1990). This discourse focuses upon ethical concerns regarding whether work is "good" or "bad", and whether the meaning of work as compulsion has crowded out the meaning of work as free, expressive and creative action (Spencer, 2009). Future research within HRD could explore the inter-relationship or differences between the 'meaning of' and 'meaningful work' for example to find out whether work that has particular 'meanings' is experienced as 'more meaningful'.

Implications for HRD Practice 
Our review of the empirical evidence relating to meaningful work suggests that a sense of meaningfulness is an important underpinning for positive work-related attitudes such as engagement, commitment and intent to remain (Fairlie, 2011). Consequently, it is important for HRD practitioners to understand more about what meaningful work is, and how a sense of meaningfulness can be fostered through organizational interventions. As Thory (2016) points out, HRD professionals have a leading role to play in the arena of meaningfulness, and so can use their expertise to guide organizational leaders.

HRD practitioners can draw on the insights from this analysis to develop evidence-based interventions in support of meaningfulness. For example, in the area of job design, ensuring jobs are designed to maximize empowerment, enrichment, task identity, task significance and skill variety will likely yield higher levels of meaningfulness. Equally, a focus on community-building and fostering a sense of belonging will help individuals to gain a sense of unity with those around them and support meaningfulness.

Learning and development interventions will be important for meaningfulness such that when employees are able to learn new skills they will gain a sense of accomplishment and feelings of self-actualization associated with higher levels of meaningful work (Chalofsky, 2010). Leadership development aimed at helping leaders and managers enhance their spiritual and transformational approaches will likely foster high levels of meaningfulness among their followers. However, HRD practitioners should bear in mind the findings from a small number of studies which suggest that employees in some occupations may find it easier to access a sense of meaningfulness than others (Lips-Wiersma et al., 2016), and therefore consider how interventions may be tailored towards the needs of specific groups. 


\section{Conclusions}

Inevitably, our study has some limitations. Although we undertook comprehensive searches of the relevant databases, coupled with manual searches and citation tracking, we cannot be fully certain we have captured all empirical studies. Meta-analyses would further supplement this review of the empirical literature by providing a detailed report on the significance of association between variables. For reasons of quality and manageability, our search focused on articles in peer-reviewed journals thereby excluding other published sources such as conference papers, book chapters or the wider grey literature. Our specific focus on the empirical evidence relating to meaningful work means that we could not consider related bodies of literature such as research on the meaning of work, callings, or job crafting and future syntheses could examine research at the interface between these topic areas.

Nevertheless, in light of the dearth of previous analysis specifically relating to meaningful work, our objective was to synthesize the existing empirical evidence base focused on this topic. In doing so, we make a contribution first by assembling, analyzing and evaluating the empirical literature on meaningful work and, second, by highlighting critical gaps and shortcomings in the evidence base, as well as by uncovering the areas where further research would help to develop the HRD field further. 


\section{References - need updating}

Ahmad, A., \& Omar, Z. (2016). Workplace spirituality among Malaysian community service employees in the public sector. Asian Social Science, 12, 193-201.

Alagaraja, M., \& Shuck, B, (2015). Exploring organizational alignment-employee engagement linkages and impact on individual performance: A conceptual model. Human Resource Development Review, 14, 17-37.

Albuquerque, I. F., Cunha, R. C., Martins, L. D., \& Sa, A. B. (2014). Primary health care services: Workplace spirituality and organizational performance. Journal of Organizational Change Management, 27, 59-82.

Allan, B. A., Autin, K. L., \& Duffy, R. D. (2016a). Self-determination and meaningful work: Exploring socioeconomic constraints. Frontiers in Psychology, 7, article 71.

Allan, B. A., Douglass, R. P., Duffy, R. D., and McCarty, R. J. (2016b). Meaningful work as a moderator of the relations between work stress and meaning in life. Journal of Career Assessment, 24, 429-440.

Arnold, K., Turner, N., Barling, J., Kelloway, E. K., \& McKee, M. C. (2007). Transformational leadership and psychological well-being: The mediating role of meaningful work. Journal of Occupational Health Psychology, 12, 193-203.

Ashmos, D., \& Duchon, D. (2000). Spirituality at work: A conceptualization and measure. Journal of Management Inquiry, 9, 34-145.

Bailey, C., \& Madden, A. (2016). What makes work meaningful - Or meaningless. MIT Sloan Management Review, Summer, 52-63.

Bailey, C., \& Madden, A. (2017). Time reclaimed: temporality and the experience of meaningful work. Work, Employment, and Society, 31, 3-18. 
Bailey, C., Madden, A., Alfes, K., \& Fletcher, L. (2015). The meaning, antecedents and outcomes of employee engagement: A narrative synthesis. International Journal of Management Reviews. DOI: 10.1111/ijmr.12077.

Bailey, C., Madden, A., Alfes, K., Shantz, A., \& Soane, E. (2016) The Mis-Managed Soul: Existential Labor and the Erosion of Meaningful Work. Human Resource Management Review, 27, 416-430.

Bassi, M., Bacher, G., Negri, L., \& Delle Fave, A. (2013). The contribution of job happiness and job meaning to the well-being of workers from thriving and failing companies. Applied Research in Quality of Life, 8, 427-448.

Baumeister, R.F. (1991). Meanings in Life. New York: Guilford.

Bergmann, J. S., Renshaw, K. D., Allen, E.S., Markman, H. J. \& Stanley, S. M. (2014). Meaningfulness of service and marital satisfaction in army couples. Journal of Family Psychology, 28, 701-706.

Berkelaar, B.L., \& Buzzanell, P.M. (2015). Bait and switch or double-edged sword? The (sometimes) failed promises of calling. Human Relations, 68, 157-178.

Both-Nwabuwe, J., Dijkstra, M.T.M., \& Beersma, B. (2017). How to define and measure meaningful work. Frontiers in Psychology. DOI: 10.3389/fpsyg.2017.01658

Bowie, N.E. (1998). A Kantian theory of meaningful work. Journal of Business Ethics, 17, 10831092.

Briner, R. B., \& Denyer, D. (2010). Systematic review and evidence synthesis as a practice and scholarship tool. In D. Rousseau (Ed.), Handbook of Evidenced-based Management: Companies, Classrooms, and Research, (pp. 328-347). Oxford: Oxford University Press. 
Britt, T. W., Adler, A. B., \& Bartone, P. T. (2001). Deriving benefits from stressful events: The role of engagement in meaningful work and hardiness. Journal of Occupational Health Psychology, 6, 53-63.

Britt, T.W., Dickinson, J.M., Castro, C.A. \& Adler, A.B. (2007). Correlates and consequences of morale versus depression under stressful conditions. Journal of Occupational Health Psychology, $12,34-47$.

Budd, J. 2011. The Thought of Work. Cornell: ILR.

Bunderson, S. J., \& Thompson, J. A. (2009). The call of the wild: Zookeepers, callings, and the double-edged sword of deeply meaningful work. Administrative Science Quarterly, 54, 32-57.

Carton, A.M. (2017). 'I'm not mopping the floors, I'm putting a man on the moon!' How NASA leaders enhanced the meaningfulness of work by changing the meaning of work. Administrative Science Quarterly, DOI: 10.1177/0001839217713748.

Chalofsky, N., \& Cavallero, L., (2013). A Good Living Versus a Good Life: Meaning, Purpose and HRD. Advances in Developing Human Resources, 15, 331-340.

Chalofsky, N., \& Krishna, V. (2009). Meaningfulness, Commitment, and Engagement: The Intersection of a Deeper Level of Intrinsic Motivation. Advances in Developing Human Resources, 11,189-203.

Chen, C-Y., \& Li, C-I. (2013). Assessing the spiritual leadership effectiveness: The contribution of follower's self-concept and preliminary tests for moderation of culture and managerial position. The Leadership Quarterly, 24, 240-255.

Chen, Z., Zhang, X., \& Vogel, D. (2011). Exploring the underlying processes between conflict and knowledge sharing: A work engagement perspective. Journal of Applied Social Psychology, $41,1005-1033$. 
Chen, H-C., Lee, A. Y-P., Chen, I-H., \& Wu, H-L. (2016). The meaningfulness of managerial work: Case of Taiwanese employees. Chinese Management Studies, 10,138-154.

Ciulla, J. B. (2000). The Working Life: The Promise and Betrayal of Modern Work. New York, NY: Random House.

Ciulla, J.B. (2012). Worthy work and Bowie's Kantian theory of meaningful work. In Arnold. D. and Harris, J. (Eds.) Kantian Business Ethics, (pp. 115-131). Northampton: Edward Elgar.

Cohen-Meitar, R., Carmeli, A., \& Waldman, D. A. (2009). Linking meaningfulness in the workplace to employee creativity. The intervening role of organizational identification and positive psychological experiences. Creativity Research Journal, 21, 361-375.

Colbert, A., Bono, J., \& Purvanova, R. (2016). Flourishing via workplace relatinoships: moving beyond instrumental support. Academy of Management Journal, 59, 1199-1223.

Daniel, J. L. (2015). Workplace spirituality and stress: Evidence from Mexico and US. Management Research Review, 38, 29-43.

Duchon, D., \& Plowman, D., A. (2005). Nurturing the spirit at work: Impact on work unit performance. The Leadership Quarterly, 16, 807-833.

Duffy, R. D., Allan, B. A., Autin, K. L., \& Bott, E. M. (2013). Calling and life satisfaction: It's not about having it, it's about living it. Journal of Counseling Psychology, 60, 42-52.

Duffy, R. D., Blake., A. A., Autin, K. L., \& Douglass, R. P. (2014). Living a calling and work well-being: A longitudinal study. Journal of Counseling Psychology, 61, 605-615.

Fairlie, P. (2011). Meaningful work, employee engagement, and other key outcomes: Implications for human resource development. Advances in Human Resources, 13, 508-525.

Fletcher, L., Bailey, C. \& Gilman, M. (2017). Fluctuating levels of personal role engagement within the working day: a multilevel study. Human Resource Management Journal. DOI: $10.1111 / 1748-8583.12168$. 
Gallie, W. B. (1956). Essentially contested concepts. Proceedings of the Aristotelian Society, 56, $167-198$.

Ganjali, A., \& Rezaee, S. (2016). Linking perceived employee voice and creativity. Iranian Journal of Management Studies, 9,175-191.

Geldenhuys, M., Taba, K., \& Venter, C. M. (2014). Meaningful work, work engagement and organizational commitment. SA Journal of Industrial Psychology, 40(1) Art. \#1098.

Ghadi, M. Y., Fernando, M., \& Caputi, P. (2013). Transformational leadership and work engagement: The mediating effect of meaning in work. Leadership and Organizational Development Journal, 34, 532-550.

Gloria, C. T., \& Steinhardt, M. A. (2016). Relationships among positive emotions, coping, resilience and mental health. Stress \& Health, 32, 145-156.

Grant, A.M. (2007). Relational job design and the motivation to make a prosocial difference. Academy of Management Review, 32, 393-417.

Gupta, M., Kumar, V., \& Singh, M. (2014). Creating satisfied employees through workplace spirituality: A study of the private insurance firms in Punjab (India). Journal of Business Ethics, $122,79-88$

Hackman, R., \& Oldham, G. R. (1975). Development of the Job Diagnostic Survey. Journal of Applied Psychology, 60,159-170.

Hackman, R., \& Oldham, G. R. (1976). Motivation through the design of work: Test of a theory. Organizational Behavior and Human Experience, 16, 250-279.

Hirschi, A. (2012). Callings and work engagement: Moderation mediation model of work meaningfulness, occupational identity and occupational self-efficacy. Journal of Counseling Psychology, 59, 479-485. 
Idaszak, J., Bottom, W. P., \& Drasgow, F. (1988). A test of measurement equivalence of the revised job diagnostic survey: Past problems and current solutions. Journal of Applied Psychology, 73, 647-656.

Isaksen, J. (2000). Constructing meaning despite the drudgery of repetitive work. Journal of Humanistic Psychology, 40, 84-107.

Johns, G., Xie, J. L., \& Fang, Y. (1992). Mediating and moderating effects in job design. Journal of Management, 18, 657-676.

Johnson, M. J., \& Jiang, L. (2016). Reaping the benefits of meaningful work: The mediating versus moderating role of work engagement. Stress \& Health, DOI 10.1002/smi.2710

Kahn, W. A. (1990). Psychological conditions of personal engagement and disengagement at work. Academy of Management Journal, 33, 692-724.

Kuchinke, K.P., Cornachione, E.B., Oh, S.Y. \& Kang, H-S. (2010). All work and no play? The meaning of work and work stress of mid-level managers in the United States, Brazil and Korea. Human Resource Development International, 13, 393-408.

Leiter, M. P., \& Harvie, P. (1997). Correspondence of supervisor and subordinate during major organizational change. Journal of Occupational Health Psychology, 2, 343-352.

Lepisto, D.A. \& Pratt, M.G. (2017). Meaningful work as realization and justification: toward a dual conceptualization. Organizational Psychology Review, 7, 99-121

Li, I-C., Chen, Y-C., \& Kuo, H-T. (2008). The relationship between work empowerment and work stress perceived by nurses at long-term care facilities in Taipei city. Journal of Clinical Nursing, 17, 3050-3058.

Lips-Wiersma, M. (2002). The influence of 'spiritual meaning-making' on career behavior. The Journal of Management Development, 21, 497-520. 
Lips-Wiersma, M., \& Morris, L. (2009). Discriminating between 'meaningful work' and the 'management of meaning'. Journal of Business Ethics, 88, 491-511.

Lips-Wiersma, M., \& Wright, S. (2012). Measuring the meaning of meaningful work: Development and validation of the Comprehensive Meaningful Work Scale (CMWS). Group and Organization Management, 37, 665-685.

Lips-Wiersma, M., Wright, S., \& Dik, B. (2016). Meaningful work: differences among blue, pink- and white collar occupations. Career Development International, 21,534-551.

Littmann-Ovadia, H., \& Steger M. (2010). Character strengths and well-being among volunteers and employees: Towards an integrative model. The Journal of Positive Psychology, 5, 419-430.

Mather, P. C. (2005). Interns at an international, humanitarian organization: Career pathways and meaning making. Journal of College Student Development, 49, 182-198.

May, D.R. (2003). Fostering the human spirit at work: toward an understanding of the influences on employees' experienced meaningfulness at work. Unpublished manuscript.

May, D. R., Gilson, R. L., \& Harter, L. M. (2004). The psychological conditions of meaningfulness, safety and availability and the engagement of the human spirit at work. Journal of Occupational and Organizational Psychology, 77, 11-37.

May, D. R., Li, C., Mencl, J., \& Huang, C.-C. (2014). The Ethics of Meaningful Work: Types and Magnitude of Job-Related Harm and the Ethical Decision-Making Process. Journal of Business Ethics, 121, 651-669

McCarthy, J., \& Friedman, L. H. (2006). The significance of autonomy in the nursing home administrator profession: A qualitative study. Health Care Management Review, 31, 55-63.

McCrae, R., Boreham, P., \& Ferguson, M. (2011). Reducing work to life interference in the public service: The importance of participative management as mediated by other work attributes. Journal of Sociology, 47, 313-332. 
Michaelson, C. (2009). Meaningful work and moral worth. Business \& Professional Ethics Journal, 1-4, 27-48.

Michaelson, C., Pratt, M.G., Grant, A.M., \& Dunn, C.P. (2014). Meaningful work: connecting business ethics and organization studies. Journal of Business Ethics, 121, 77-90.

Miller, J. G., \& Wheeler, K. G. (1992). Unravelling the mysteries of gender differences in intentions to leave the organization. Journal of Organizational Behavior, 13, 465-478.

Mitra, R., \& Buzzanell, P. M. (2017). Communicative tensions of meaningful work: The case of sustainability practitioners. Human Relations, 70, 594-616.

Montani, F., Boudrias, J-S., \& Pigeon, M. (2017). Employee recognition, meaningfulness and behavioural involvement: Test of a moderated mediation model. The International Journal of Human Resource Management, 1-29.

Mottaz, C.J. (1981). Some determinants of work alienation. Sociological Quarterly, 22, 515-529. Munn, S. L. (2013). Unveiling the work-life system: The influence of work-life balance on meaningful work. Advances in Developing Human Resources, 15, 401-407.

Nair, N., \& Vohra, N. (2010). An exploration of factors predicting work alienation of knowledge workers. Management Decision, 48, 600-615.

Pavlish, C., \& Hunt, R. (2012). An exploratory study about meaningful work in acute care nursing. Nursing Forum, 47, 113-122.

Piccolo, R. F., \& Colquitt, J. A. (2006). Transformational leadership and job behaviors: The mediating role of core job characteristics. Academy of Management Journal, 49, 327-340.

Pollet, E., \& Schnell, T. (2016). Brilliant: But what for? Meaning and subjective well-being in the lives of intellectually gifted and academically high achieving adults. Journal of Happiness Studies, 1-26. doi:10.1007/s10902-016-9783-4. 
Pradhan, S., \& Pradhan, R. K. (2016). Transformational leadership and job outcomes: The mediating role of meaningful work. Global Business Review, 17, supplement 173-185.

Rafferty, A. E., \& Restubog, S. L. D. (2011). The influence of abusive supervisors on followers' organizational citizenship behaviours: The hidden costs of abusive supervision. British Journal of Management, 22, 270-285.

Rasmussen, V., Turnell, A., Butow, P., Juraskova, I., Kirsten, L., Wierner, L., ... IPOS Research Committee. (2016). Burnout among psychosocial oncologists: An application and extension of the effort-reward imbalance model. Psychooncology, 25, 194-202.

Renard, M., \& Snelgar, R. J. (2016). How can work be designed to be intrinsically rewarding? Qualitative insights South African non-profit employees. SA Journal of Industrial Psychology, $42,1346$.

Rosso, B. D., Dekas, K. H., \& Wrzesniewski, A. (2010). On the meaning of work: A theoretical integration and review. Research in Organizational Behavior, 30, 91-127.

Schnell, T. (2011). Individual Differences in Meaning-Making: considering the variety and sources of meaning, their density and diversity. Personality and Individual Differences, 51, 667673.

Schnell, T., Höge, T., \& Pollet, E. (2013). Predicting meaning in work: Theory, data, implications. The Journal of Positive Psychology, 8, 543-554.

Scroggins, W. A. (2008). Antecedents and outcomes of experienced meaningful work: A personjob fit perspective. Journal of Business Inquiry: Research, Education and Application, 7, 68-78.

Shuck, B. (2011), Four Emerging Perspectives of Employee Engagement: An Integrative Literature Review. Human Resource Development Review, 10, 304-328. 
Soane, E., Shantz, A., Alfes, K., Truss, K., Rees, C., \& Gatenby, M. (2013). The association of meaningfulness, well-being and engagement with absenteeism: A moderated mediation model. Human Resource Management, 52, 441-456.

Spreitzer, G. M. (1995). Psychological empowerment in the workplace: Dimensions, measurement and validation. Academy of Management Journal, 38,1442-1465.

Steger, M. F., Frazier, P., Oishi, S., \& Kaler, M. (2006). The meaning in life questionnaire: Assessing the presence of and search for meaning in life. Journal of Counseling Psychology, 53, 80-93.

Steger, M. F., Dik, B. J., \& Duffy, R. D. (2012). Measuring meaningful work: The Work and Meaning Inventory (WAMI). Journal of Career Assessment, 20, 322-337.

Steger, M. F., Littmann-Ovadia, H., Miller, M., Menger, L. \& Rothmann, S. (2013). Engaging in work even when its meaningless: Positive affective disposition and meaningful work interact in relation to work engagement. Journal of Career Assessment, 21, 348-361.

Tablan, F. (2015). Catholic social teachings: toward a meaningful work. Journal of Business Ethics, 128, 291-303.

Taylor, M. (2017). Good work: the Taylor review of modern working practices. Independent Report, 11 July. London: Department for Business, Energy and Industrial Strategy.

Thory, K. (2016). Developing meaningfulness at work through emotional intelligence training. International Journal of Training \& Development, 20,58-77.

Tims, M., Derks, D., \& Bakker, A. B. (2016). Job crafting and its relationship with person-job fit and meaningfulness: A three-wave study. Journal of Vocational Behavior, 92, 44-53.

Torp, S., Vinje, H.F. \& Haaheim-Simonsen, H.K. (2016). Work, well-being and presence among researchers. International Journal of Mental Health Promotion, 18, 199-212. 
Treadgold, R. (1999). Transcendent vocations: Their relationship to stress, depression and clarity of self-concept. Journal of Humanistic Psychology, 39, 81-105.

Tummers, L. G., \& Knies, E. (2013). Leadership and meaningful work in the public sector. Public Administration Review, 73, 859-868.

Veltman. A. (2016). Meaningful Work. Oxford: Oxford University Press.

Viera, A.J. \& Garrett, J.M. (2005). Understanding inter-observer agreement: The kappa statistic. (Family Medicine). Research Series, 37, 360-363.

Weeks, K. \& Schaffert, C. (2017). Generational differences in definitions of meaningful work: a mixed methods study. Journal of Business Ethics, DOI: 10.1007/s 10551-017-3621-4

Wolf, S. (2010). Meaning in Life and Why it Matters. Princeton, NJ: Princeton University Press.

Woodard, M. S., Miller, J. K., Miller, D., Silvernail, K. D., Guo, C., Nair, S., \& Peters, L. M. (2016). A cross- cultural examination of preferences for work attributes. Journal of Managerial Psychology, 31, 702-719.

Yeoman, R. (2014). Conceptualising meaningful work as a fundamental human need. Journal of Business Ethics, 125, 235-251. 